\title{
Cost Effective Protocol for In Vitro Culture of Chlorophytum Borivilianum Sant. Et Fernand.
}

\author{
U.S. Sharma, Mangesh Kumar Mankar, Maya Singh \\ Department of Research \& Development, Madhya Pradesh Vigyan Sabha, Gyan Vigyan Parisar, Sagoni Kala, \\ Raisen Road, Bhopal - 462021MP
}

\begin{abstract}
Chlorophytum borivilianum belonging to the family Liliaceae is commonly known as safed musli. It is a perennial rhizomatous herbs widely distributed in pan tropical region which containing pharmaceutical important compound saponins. Safed musli is an endangered medicinal herb value for its dried roots possesses immune-modulatory and aphrodisiac properties that form an important ingredient of herbal tonic. Root culture, callus established from micro propagated plants of C.borivilianum on MS medium supplemented with $1 \mathbf{m g} / \mathbf{l}$ $I B A+10 \% C M \& 0.5 \mathrm{mg} / \mathrm{l} \mathrm{2,} \mathrm{4+15 \% CM}$ and Leaf base \& Root are explants. Growth kinetics of explants done under portable incubation chamber where natural ambient light, temperature and relatively humidity are controlled. Maximum biomass observed after 39 days of inoculation after sub culturing of these culture root growth shown and even number of roots increased from one to three. Resulted cost reduction on electricity \& synthetic hormones in micro propagation compared to the generally used PTC technology \& large scale of carbon emission in the atmosphere and polluted to the environment can be controlled by use of this protocol.
\end{abstract}

Keywords: Chlorophytum borivilliaunm (Safed musli), Murashige and Skoog, Indole Butyric Acid, Coconut milk, Plant tissue culture, carbon emission.

\section{Introduction}

Tuberous roots of Chlorophytum borivilianum (commonly known as safed musli) family Liliaceae possess immunomodulatory and adaptogenic properties and are used to cure impotency, sterility and enhance male potency $[1,2]$. C. borivilianum, an endangered plant in its natural habitat, is an important herbaceous medicinal plant of Central India-Madhya Pradesh, Rajasthan and Gujarat. Its roots are fascicled, sessile, and cylindrical are of variable sizes and shapes. After peeling and drying, these fleshy roots popularly known as Safed Musli are used in more than a hundred Ayurvedic preparations and prescribed primarily as a tonic against stress and general debility [3]. The secondary metabolites or active ingredients found in this plant are sapogenins and steroids [4]. The extract of dried root tubers of $C$. borivilianum acts as psycho stimulant and has a beneficial effect on the brain and human body by increasing alertness, mental ability, intelligence and sexual characters. Its seeds have poor germination percentage (11-24\%), low viability and long dormancy period, slow growth/establishment, seed propagation is restricted. Safed musli is propagated vegetatively by fleshy tuberous roots bearing shoot buds. Micro propagation technology is advantageous due to production of high-quality disease-free, true-to type plants independent of seasonal and other environmental conditions in a comparatively smaller space [5]. But higher cost of plant production has always limited the use and exploitation of this technique at industrial level [6]. To overcome this limitation, cost-reduction strategies have been employed [7]. Micro-propagation of $C$. borivilianum on solid medium has been reported earlier [8-9]. For scale-up cultures using bioreactors, the use of liquid culture medium has been recommended [10-11]. The physical state of the culture medium and its composition affect the in vitro growth of plants to a great extent. The most commonly used gelling agent-agar (adding up to 65\% of the cost of the culture medium) results in local accumulation of heat and hinders the access of dissolved oxygen to the cultured cells [12]. By employing liquid culture medium, reduction in plant production cost can be achieved [13, 15]. The advantages of liquid culture medium for enhancing shoot proliferation and growth have been reported in several plant species [16-19]. All research scholars have used expensive media, growth regulators and incubated culture under controlled environment requires continuous high energy. We filled this gap by developing homemade media, supplement with natural growth regulator like coconut milk because liquid fertilizer produced locally by bio-degradation of green weeds having all nutrients and incubation has done under natural ambient light, temp, humidity without using any Air Conditioned incubation room which is free from micro organism. Therefore we have utilized alternative low cost culture pots, media, and environment condition etc for developing plant lets of Chlorophytum spp. Our research assumption based on species which grown in tropical region on $35-40^{\circ} \mathrm{C}$ which do not require $22 \pm 2{ }^{\circ} \mathrm{C}$ temperature means it do not require any Air Conditioned facility. We have conducted ecological survey in MPCA Area of Karhal range in Sheopur forest division and observed that 25 years back its production was 100 qt in entire block now it has reduced to only $5-10 \mathrm{kgs}$ while it has great economical, ecological and medical value. 


\section{Expalnt collection:}

\section{Materials And Methods}

Plants of $C$. borivilianum were collected from natural habitat forest area of Karhal block of district Sheopur in last week of August, 2012 were maintained in our campus Madhya Pradesh Vigyan Sabha Bhopal. In vitro cultures were established from young shoot apices, leaf base and roots obtained from the tuberous roots of this field grown plants. Healthy plants were selected for in vitro culture.

\section{Sterilization of explant:}

In Open lab condition selected plants washed thoroughly with tap water to remove soil adhered to it. Approximately $1.5-2 \mathrm{~cm}$ pieces of root top with crown meristem, leaf base were cut and kept in $2 \%$ Tween-20 solution for 30 minutes and then washed with D/W. Explants were dipped in a solution containing $0.1 \%$ Bavestin (Fungicide) and $0.25 \%$ Chloramphenicol (bactericide) and kept on a shaker for 30 min.

In Closed lab condition The crown part of tuberous roots were cut $1 \mathrm{~cm}$ below the apex and surface sterilized in a laminar flow bench. Each explant was treated separately, because being a field grown plant it has higher microbial load. Explants were dipped into 1\% sodium hypochlorite solution for 10 min and then rinsed with autoclaved D/W. They were then immersed into $0.2 \%$ mercuric chloride solution for 4 min and then rinsed thrice with sterilize distilled water. The explants were further trimmed to $0.5 \mathrm{~cm}$ cube without damaging the apical meristem.

\section{Media Preparation}

MS medium having 3\% sucrose and solidified with $0.8 \%$ agar (Himedia, India). Our alternative micro propagation technology utilized natural easily available media.

Table1. Effect of physical state of medium on growth and shoot multiplication of in vitro cultured shoots of Chlorophytum borivilianum.

\begin{tabular}{|l|l|l|l|}
\hline TT & Inoculation period & Explants & Media Composition \\
\hline T1 & $21 / 07 / 14$ & LB & MS+0.5 mg/1 2, 4 D + 15 \% CM \\
\hline T2 & $20 / 07 / 14$ & R+ LB \& Stem & $1 / 2 \mathrm{MS}+1 \mathrm{mg} / 1 \mathrm{IBA}+10 \% \mathrm{CM}$ \\
\hline T3 & $22 / 07 / 14$ & Stem, LB \& R & MS+0.5mg/l IBA+5\%CM \\
\hline T4 & $29 / 08 / 14$ & Sub culture of \& T2 & MS+2 mg/l IBA + 15\% CM \\
\hline T5 & $02 / 08 / 14$ & Subculture of \& T3 & MS+1mg/IBA+5\%CM \\
\hline
\end{tabular}

*R-Root, LB-Leaf Base, CM-Coconut milk, mg/1- mg per liter

Murashige and Skoog (MS) basal medium supplemented with 3\% w/v sucrose are used with supplement coconut milk (natural cytokine), BAP, 2, 4 D, IAA and IBA at different concentration and different composition with $0.8 \%$ agar or without agar (liquid medium) was used. The $\mathrm{pH}$ of the medium was adjusted to $5.80 \pm 0.1$ using $0.10 \mathrm{~N} \mathrm{HCl}$ and/or $0.10 \mathrm{~N} \mathrm{NaOH}$ than autoclaving at $121^{\circ} \mathrm{C}$ temperature and $15 \mathrm{lb}$ pressure for 20 min.

Inoculation \& Incubation: Inoculation has done under laminar air flow, two explants were inoculated per culture flask and cultures incubated in Portable incubation chamber where natural ambient light, temperature and humidity are controlled, although we measured temperature and humidity i.e. from $25-28^{\circ} \mathrm{C}$ and Relative Humidity from 70-82\% (Thermo/Hydro/Clock 288-CTH) in the month of July.

Observation: Observations were recorded after 40 days of culture period.

\section{Result}

Callus Induction: - Different explants much like leaf base, root, \& stem tried for callus initiation on MS media supplement with different concentration of 2, $4 \mathrm{D} \& \mathrm{CM}$. but only Leaf base responded for callus induction on $\mathrm{T} 1$ (MS+0.5 mg/1 2, $4 \mathrm{D}+15 \% \mathrm{CM}$ ) media composition.

\section{Root Induction:-}

T2 having 1/2 MS+1 mg/l IBA + 10\% CM media composition and Leaf base \& Root are explants. Root initiation began in leaf base after 39 days of inoculation. When the initiated cultures (Fig. 1a) were subculture on higher concentration of hormones in T4 $(2 \mathbf{~ m g} / \mathbf{l}$ IBA $+\mathbf{1 5 \%} \mathbf{C M})$ proliferation began within a month, number of roots increased from 1 to 3 (Fig. 1b).

Shoot Induction: - Shooting initiation shown in T3 (MS+0.5mg/l IBA+5\% CM) \& T5 (MS+1mg/I IBA+5\% CM) after 10 days of inoculation and after 20 days 3 leaves emerged. 


\section{Discussion}

The C. borivilliaum plant, and especially its roots, has been used for centuries in folk medicine as an aphrodisiac tonic. The present study is an attempt to test the low cost protocol for micro propagation of $C$. borivilliaum. Our present study supports previous finding report on coconut milk which shows cytokinins activity by Kuraishi \& Okumora (1961) and Lentham (1966) recognized natural cytokine substance which has been isolated from Coconut milk [9-B-D-ribo-furanosyl-Zeatin]. Coconut milk was first used in plant tissue culture by Van Overbeek etal (1941) \& found that it's the addition to the culture medium was necessary for the development of very young embryo of Dhatura stramonium than Gautheret (1942) found that the coconut milk could be used to initiate and maintain growth in tissue couture of several plants..Growth regulators are expected to control the production of adventitious root in plant.

\section{Conclusion}

The result of our study proves that, in vitro grown cultures of $C$. borivilliaum used natural hormone and cultures incubate in lost cast Portable incubation chamber where temperature, natural ambient light and relative humidity are controlled. Therefore we can reduce energy consumption \& can use easily availed growth regulator like coconut milk in the place synthetic hormones. Because plant tissue culture is a highly energy consuming technology especially incubate at low temperature which requires Air Conditioner. We are developed lost cast Portable incubation chamber where culture were inoculated, base use Presently fourth part of cost for plant tissue culture consumes only for creating Air Condition facility from total cost. Recently 0.00054 tons of coal used to generate one kilowatt-hour (kWh) of electricity so large scale of carbon emission in the atmosphere which pollutes the environment. So we filled this gap by developing cost effective protocol for micro propagation of $C$. borivilliaum without using Air Conditioned Lab facility. Micro propagation has great potential as a tool for rising elite plants which provide raw material for traditional medicines. Protocols have been developed for the multiplication of elite plant species for medicinal and aromatic uses in several labs all over the country.

\section{Acknowledgement}

We are grateful to Madhya Pradesh Council of Science and technology, Bhopal for providing financial assistance to conduct this research work.

\section{References}

[1]. Mimaki, Kanmato, T., Sashida, Y., Nishino, A., Satomi, Y.and Nishino, H., Steroidal saponins from the undergo parts of Chlorophytum borivilianum comosum and their inhibitory activity on tumor promoter-induced phospholipids metabolisum of HeLa cells. Phytochemistry, 1996, 41, 1405-1410.

[2]. Qiu, S.-X. et al., Isolation and characterization of cytotoxic saponin chloromaloside A from Chlorophytum malayense. Planta Med., 2000, 66, 587-590.

[3]. Bordia, P.C., Joshi, A., Simlot, M.M. Safed Musli. In: Chadha, K.L., Gupta, R. (Eds.) Advances in Horticulture. Vol.11-Medicinal and Aromatic Plants. Malhotra Publishing House, New Delhi. 1995.

[4]. Kitply Industry, Agro-forestry Division Report. Presence of hezoxymine \& asparagin in Chlorophytum.

[5]. Debergh, P. C. and Zimmerman, R. H., Micro propagation: Technology and Application, Kluwer, Dordrecht, 1991.

[6]. Kozai, T., Kubota, C. and Jeong, B. R., Environmental control for the large scale production of plants through in vitro techniques. Plant Cell, Tissue Organ Cult., 1997, 51, 49-56.

[7]. Levin, R. and Vasil, I. K., Progress in reducing the cost of micro propagation. IAPTC Newsl. 1989, 59, 2-12.

[8]. Purohit, S. D., Dave, A. and Kukda, G., Micro propagation of safed musli (Chlorophytum borivilianum), a rare Indian medicinal herb. Plant Cell Tissue Organ Cult., 1994, 39, 93-96.

[9]. Dave, A., Bilochi, G. and Purohit, S. D., Scaling-up production and field performance of micro propagated medicinal herb 'safed musli' (Chlorophytum borivilianum). In Vitro Cell. Dev. Biol. 2003, 39, 419-424.

[10]. Kim, E. K., Hahn, E. J., Murthy, H. N. and Paek, K. Y., Enhanced shoot and bulblet proliferation of garlic (Allium sativum L.) in bioreactor systems. J. Hortic. Sci., 2004, 79, 818-822.

[11]. Akita, M., Shigeoka, T., Koizumi, Y. and Kawamura, M., Mass propagation of shoots of Stevia rebaudiana using a large-scale bioreactor. Plant Cell Rep., 1994, 13, 180-183.

[12]. Paek, K. Y., Chakrabarty, D. and Hahn, E. J., Application of bioreactor systems for large scale production of horticultural and medicinal plants. Plant Cell Tissue Organ Cult, 2005, 81, 287-300.

[13]. Kohlenbach, H. W. and Wernicke, W., Investigations on the inhibitory effect of agar and the function of active carbon in anther culture. Z. Pflanzenphysiol., 1978, 86, 463-472.

[14]. Paque, M., Bercetche, J. and Dumas, E., Liquid media to improve and reduce the cost of in vitro conifer propagation. Acta Hortic., 1992, 319, 95-100.

[15]. Rizvi, M. Z., Kukreja, A. K., Khanuja, S. P., In vitro culture of Chlorophytum borivilianum Sant. et Fernand. In liquid culture medium as a cost-effective measure. Current Science, 2007, VOL. 92, 87-90.

[16]. Bhagyalakshmi and Singh, N. S., Role of liquid versus agar-gelled media in mass propagation and ex vitro survival in bananas. Plant Cell Tissue Organ Cult., 1995, 41, 71-73.

[17]. Chu, C. Y., Knight, S. L. and Smith, M. A. L., Effect of liquid culture on the growth and development of miniature rose (Rosa chinensis Jacq. 'Minima'). Plant Cell Tissue Organ Cult., 1993, 32, 329- 334.

[18]. Sandal, I., Bhattacharya, A. and Ahuja, P. S., An efficient liquid culture system for tea shoot proliferation. Plant Cell Tissue Organ Cult, 2001, 65, 75-80. 
[19]. Kim, E. K., Hahn, E. J., Murthy, H. N. and Paek, K. Y., High frequency of shoot multiplication and bulblet formation of garlic in liquid cultures. Plant Cell Tissue Organ Cult, 2003, 73, 231-236.

[20]. Dave, A., Bilochi, G and Purohit, S.D., Scaling-up production and field performance of micro propagated medicinal herbs 'safed musli' (Chlorophytum borivilliaum), in vitro cell. Dev. Biol., 2003, 39, 419-424.

[21]. KURAISHI S. \& OKUMURA F.S. A new green-leaf growth, stimulating factor, phyllococosine, from coconut milk. Nature, 1961, 189, 148-149.

[22]. GAUTHERET R.J. Manuel Technique de Culture des Tissue.Végétaux. Masson et Cie, 1942, Paris.

[23]. VAN OVERBEEK J., CONKLIN M.E. \& BLAKESLEE A.F. 1941 Factors in coconut milk essential for growth and development of very young Datura embryos. Science 94, 350-351.

[24]. LETHAM D.S. 1966 Regulation of cell division in plant tissues. II. A cytokinin in plant extracts: isolation and interaction with other growth regulators. Phytochemistry 5, 269-286.

[25]. http://www.eia.gov/tools/faqs/faq.cfm?id=667\&t=6 